\title{
Effects of cold air inhalation on body temperature, respiratory and cerebrovascular responses during exercise in the heat
}

\author{
Bun Tsuji ${ }^{1,2,3}$, Yorinobu Chinda ${ }^{2}$, Yasushi Honda ${ }^{2}$, Naoto Fujii ${ }^{2}$, Narihiko Kondo ${ }^{3}$, Takeshi Nishiyasu ${ }^{2 *}$ \\ From 15th International Conference on Environmental Ergonomics (ICEE XV) \\ Portsmouth, UK. 28 June - 3 July 2015
}

\begin{abstract}
Introduction
Hyperthermia during exercise leads to increases in ventilation independently of metabolic factors, resulting in hypocapnia and cerebral hypoperfusion [1], which is one of the mechanisms behind impaired exercise performance in the heat. To suppress hyperthermia, cold water immersion and ingestion of cold drinks are commonly used, but the effect of cold air inhalation on physiological responses during hyperthermia is not well understood. This study examined the effects of cold air inhalation on body temperature, respiratory and cerebrovascular responses during exercise in the heat.
\end{abstract}

\section{Method}

Twelve male subjects [age $24 \pm 4$ years, height $174 \pm 4 \mathrm{~cm}$, weight $70 \pm 4 \mathrm{~kg}$, peak oxygen uptake $\left(\mathrm{VO}_{2 \text { peak }}\right) 48.5 \pm 6.5$ $\left.\mathrm{mL} \cdot \mathrm{kg}^{-1} \cdot \mathrm{min}^{-1}\right]$ performed a cycle exercise at $50 \%$ of $\mathrm{VO}_{2 \text { peak }}$ in the heat $\left(38{ }^{\circ} \mathrm{C}\right.$ ambient temperature and $50 \%$ relative humidity) until their esophageal temperature $\left(\mathrm{T}_{\mathrm{es}}\right)$ reached $39^{\circ} \mathrm{C}$ or they could no longer continue the exercise. Throughout the exercise on two separate occasions, subjects inhaled room air (i.e., $38^{\circ} \mathrm{C}$; Hot-air trial) or cold air $\left(10{ }^{\circ} \mathrm{C}\right.$; Cold-air trial). $\mathrm{T}_{\mathrm{es}}$, minute ventilation, respiratory gases, sweat rate (ventilated capsule method) and skin blood flow (laser-Doppler) on the chest, middle cerebral artery blood velocity (transcranial Doppler ultrasound) and arterial blood pressure were measured continuously.

\section{Results}

Exercise duration was higher in the Cold- than Hot-air trial $(57.1 \pm 13.7$ vs. $45.8 \pm 6.7 \mathrm{~min}, P<0.01) . \mathrm{T}_{\text {es }}$ was lower in the Cold- than Hot-air after 35 min of exercise

\footnotetext{
* Correspondence: nisiyasu@taiiku.tsukuba.ac.jp

${ }^{2}$ Institute of Health and Sport Sciences, University of Tsukuba, Japan

Full list of author information is available at the end of the article
}

$(P<0.01)$. Cutaneous vascular conductance (skin blood flow/mean arterial pressure) and $\mathrm{VO}_{2}$ did not differ between trials $(P=0.57$ and 0.22 , respectively), but sweat rate was lower in the Cold-air trial $(P=0.032)$. Minute ventilation was lower $(P=0.011)$ and estimated $\mathrm{PaCO}_{2}$ was higher $(P=0.015)$ in the Cold- than Hot-air trial. Ventilatory sensitivity to rising $\mathrm{T}_{\mathrm{es}}$ (slope of the $\mathrm{T}_{\mathrm{es}}$ ventilation relation) was similar between Hot- and Coldair trials $\left(10.3 \pm 7.7\right.$ vs. $\left.10.7 \pm 9.2 \mathrm{~L} \cdot \mathrm{min}^{-1} .{ }^{\circ} \mathrm{C}^{-1}, P=0.71\right)$. Cerebral vascular conductance (middle cerebral artery blood velocity/mean arterial pressure) was higher in the Cold-air trial $(P=0.049)$.

\section{Discussion}

Consistent with a previous study in which cold air inhalation during hyperthermic exercise decreased core temperature mainly due to increases in respiratory heat exchange (2), we found lower $\mathrm{T}_{\text {es }}$ in the Cold-air trial. We also found that cold air inhalation induced the lower ventilation but similar ventilatory sensitivity to rising $\mathrm{T}_{\text {es }}$ compared to Hot-air. These suggest that the lower ventilation during cold air inhalation was solely due to decreases in $\mathrm{T}_{\mathrm{es}}$. In addition, it was reported that reduction in cerebral blood flow velocity during exercise in the heat is largely accounted for by the hyperventilation-induced decrease in $\mathrm{PaCO}_{2}$ (3). Thus, the increases in cerebral vascular conductance in the Cold-air trial was likely attributable to cold air inhalation-induced suppressions of hyperventilation and hypocapnia.

\section{Conclusion}

Present results indicate that during prolonged exercise in the heat, cold air inhalation mitigates changes in core temperature, ventilation and cerebral blood flow. 


\section{Authors' details}

${ }^{1}$ Research Fellow of Japan Society for the Promotion of Science, University of Tsukuba, Japan. ${ }^{2}$ Institute of Health and Sport Sciences, University of

Tsukuba, Japan. ${ }^{3}$ Faculty of Human Development, Kobe University, Japan.

Published: 14 September 2015

\section{References}

1. Tsuji B, et al: Voluntary suppression of hyperthermia-induced hyperventilation mitigates the reduction in cerebral blood flow velocity during exercise in the heat. Am J Physiol Regul Integr Comp Physiol 2015, 308: R669-679.

2. Geladas N, Banister EW: Effect of cold air inhalation on core temperature in exercising subjects under heat stress. J Appl Physiol 1988, 64:2381-2387.

3. Hayashi $\mathrm{K}$, et al: Effect of $\mathrm{CO}_{2}$ on the ventilatory sensitivity to rising body temperature during exercise. J Appl Physiol 2011, 110:1334-1341.

doi:10.1186/2046-7648-4-S1-A128

Cite this article as: Tsuji et al:: Effects of cold air inhalation on body

temperature, respiratory and cerebrovascular responses during exercise in the heat. Extreme Physiology \& Medicine 2015 4(Suppl 1):A128.

\section{Submit your next manuscript to BioMed Central} and take full advantage of:

- Convenient online submission

- Thorough peer review

- No space constraints or color figure charges

- Immediate publication on acceptance

- Inclusion in PubMed, CAS, Scopus and Google Scholar

- Research which is freely available for redistribution

Submit your manuscript at www.biomedcentral.com/submit
Ciomed Central 